Arq. Bras. Med. Vet. Zootec., v.66, n.5, p.1585-1591, 2014

\title{
Identificação de Mycobacterium bovis em carcaças de bovinos abatidos no estado da Bahia, Brasil, por métodos bacteriológico e molecular
}

\author{
[Identification of Mycobacterium bovis in carcasses of cattle slaughtered in Bahia state, \\ Brazil by bacteriological and molecular methods] \\ F. Alzamora Filho' ${ }^{1}$, V.M. Reis ${ }^{2}$, I. Fehlberg ${ }^{3}$, A.C. de Alcântara ${ }^{3}$, M.P. Cavalcante ${ }^{2}$, \\ V.C.F. Rocha ${ }^{4}$, J.N. Costa ${ }^{5}$ \\ ${ }^{1}$ Universidade Estadual de Santa Cruz, DCAA - Ilhéus, BA \\ ${ }^{2}$ Escola de Medicina Veterinária e Zootecnia - UFBA - Salvador, BA \\ ${ }^{3}$ Universidade Federal da Bahia - Instituto de Ciências da Saúde - Salvador, BA \\ ${ }^{4}$ Faculdade de Medicina Veterinária e Zootecnia- USP - São Paulo, SP \\ ${ }^{5}$ Universidade Federal do Recôncavo Baiano - Cruz das Almas, BA
}

\begin{abstract}
RESUMO
O objetivo do presente trabalho foi utilizar métodos bacteriológicos e moleculares para a identificação do Mycobacterium bovis em lesões observadas em carcaças de bovinos durante a inspeção post mortem de rotina em matadouros-frigoríficos com serviço de inspeção oficial. Foram acompanhados o abate e a inspeção de 825.394 bovinos, sadios, ao exame ante mortem pelo serviço de inspeção oficial em 10 matadouros-frigoríficos do estado da Bahia, entre abril de 2009 e abril de 2012. Cento e oitenta bovinos apresentaram lesões sugestivas de tuberculose e outras linfadenites, as quais foram avaliadas quanto à presença de Mycobacterium bovis por exame bacteriológico e pela PCR multiplex. A maioria das lesões estava localizada em linfonodos do trato respiratório e $71 \%$ eram provenientes de bovinos machos com até 32 meses de idade. No isolamento bacteriano, 13,9\% (25/180) das amostras apresentavam colônias pequenas, de superfície granular e de coloração creme-amareladas, em meio de cultura Stonebrink-Leslie, e o crescimento médio foi de 34 dias. Todos os esfregaços dos isolados evidenciaram BAAR, e, pela PCR multiplex, 56\% (14/25) dos isolados foram identificados como M. bovis. A associação entre exame post mortem, bacteriológico e PCR multiplex permitiu a identificação do agente de forma rápida e em regiões com status sanitário de baixa prevalência, demonstrando ser importante para a detecção dos focos de tuberculose bovina e o auxílio nos programas de controle e erradicação da tuberculose.
\end{abstract}

Palavras-chave: Mycobacterium bovis, PCR, bacteriologia, BAAR, bovino

\begin{abstract}
The aim of the present study was to perform bacteriological and molecular methods for identification of Mycobacterium bovis in lesions derived from bovine carcasses detected during routine post-mortem examination in officially inspected slaughterhouses. We checked the slaughter and inspection of 825,394 bovines, health upon ante-mortem examination, by the official service in 10 slaughterhouses of Bahia state from April, 2009 to April 2012. Lesions suggestive of tuberculosis were collected from 180 bovines and further evaluated by bacteriology and multiplex PCR. The majority of lesions were located in the respiratory tract lymph nodes and $71 \%$ were from male bovines up to 32 months old. $13.9 \%$ of samples presented small, granular and creamy-yellowish colonies after being cultured in Stonebrink-Leslie with an average growth time of 34 days. All smears from the isolated samples were Acid Fast Bacilli (AFB) and among them 56\% were identified by $\mathrm{mPCR}$ as M. bovis. Thus, the association between post-mortem examination, culture and multiplex PCR allowed the bacillus identification in a reduced time and in
\end{abstract}

Recebido em 18 de março de 2013

Aceito em 20 de dezembro de 2013

E-mail: alzafilho@yahoo.com.br 
regions of low prevalence, pointing out its importance for bovine tuberculosis detection and as a supportive tool for the tuberculosis control and eradication program.

Keywords: Mycobacterium bovis, PCR, bacteriology, acid fast bacilli, bovine

\section{INTRODUÇÃO}

A tuberculose bovina é uma zoonose de evolução crônica causada pelo Mycobacterium bovis, que pertence ao complexo Mycobacterium tuberculosis. Caracteriza-se pelo desenvolvimento de lesões granulomatosas nodulares, denominadas tubérculos, as quais podem estar localizadas em qualquer órgão, mas com distribuição predominante no trato respiratório e nos gânglios linfáticos bronquiais e mediastínicos e ocasionalmente nos intestinos, fígado, baço, pleura e peritônio (Brasil, 2006; Heinemann et al., 2008).

A importância econômica atribuída à doença bovina está baseada nas perdas diretas resultantes da morte de animais, da redução no ganho de peso, da diminuição na produção de leite e do descarte precoce de animais de alto valor zootécnico (Pacheco et al., 2009). Os principais fatores que favorecem a transmissão dessa doença no rebanho são: elevada densidade, permitindo o contato entre os bovinos, principalmente os leiteiros criados em sistemas semi-intensivo e intensivo; presença de um animal portador, manejo, raça, idade e resistência do agente às condições ambientais favoráveis (Oliveira et al., 2008).

No Brasil, a tuberculose bovina é endêmica e afeta grande parte das propriedades leiteiras, em razão de os animais serem submetidos ao confinamento e da elevada demanda metabólica. Não há, no país, publicações oficiais atualizadas de inquéritos epidemiológicos da prevalência da tuberculose bovina, entretanto, na última estimativa, os dados indicaram uma prevalência média nacional de 1,3\% de animais reagentes à tuberculina no período de 1989 a 1998. Com o intuito de reduzir a prevalência e a incidência da doença nos rebanhos bovinos, o Ministério da Agricultura Pecuária e Abastecimento instituiu, em 2001, o Programa Nacional de Controle e Erradicação da Brucelose e Tuberculose Bovina (PNCEBT) (Brasil, 2006).

A pecuária tem expandido significativamente nas últimas décadas, representando um relevante setor na economia do Brasil, e o rebanho bovino da Bahia, 10.528.419 cabeças, o equivalente a $36,6 \%$ do efetivo do Nordeste, contribui para a crescente importância do agronegócio no estado (Instituto..., 2010). Esse crescimento torna cada vez mais necessário o incremento do controle sanitário nos rebanhos. $\mathrm{O}$ inquérito epidemiológico da tuberculose no estado da Bahia, realizado entre outubro de 2008 e novembro 2010, revelou uma prevalência de foco de TB e de animais reagentes com idade maior ou igual a 24 meses de 1,6\% e 0,21\%, respectivamente (Costa, 2012). Segundo Araújo (2004), estudos realizados no país, com base em exames de carcaças em matadouros-frigoríficos, estimaram uma prevalência de tuberculose bovina de $0,17 \%$ em Minas Gerais, 5,16\% no Pará e $0,64 \%$ no Rio Grande do Sul. Esta diferença está relacionada ao grau de desenvolvimento regional, principalmente no que se refere ao estabelecimento de medidas sanitárias no rebanho.

A inspeção post mortem dos animais destinados ao consumo nos abatedouros tem grande relevância na vigilância epidemiológica da tuberculose e, por meio desta medida, países endêmicos que possuem satisfatório desempenho nos seus serviços de inspeção nos abatedouros, associado a um consolidado programa de erradicação, têm conseguido reduzir a prevalência da doença, pois o diagnóstico precoce é a chave para o controle e a erradicação do M. bovis (Kantor e Ritacco, 2006). Biffa et al. (2010) também relataram que a identificação de alterações anatomopatológicas sugestivas de tuberculose durante a inspeção post mortem nos matadouros-frigoríficos, juntamente com a realização dos métodos diretos de diagnóstico da infecção, são importantes ferramentas na vigilância epidemiológica.

Diversos estudos vêm demonstrando a possibilidade do uso da PCR no diagnóstico da tuberculose bovina, permitindo maior acurácia e significativa redução do tempo do diagnóstico em relação aos métodos tradicionais de identificação (Cardoso et al., 2009; Furlanetto et al., 2012; Adams et al., 2013). 
O presente estudo teve por objetivo estimar a ocorrência de tuberculose em bovinos do estado da Bahia, por meio da inspeção post mortem em matadouros-frigoríficos sob inspeção oficial, utilizando como diagnóstico confirmatório das lesões suspeitas os exames bacteriológicos e PCR multiplex (m-PCR) para identificação dos isolados.

\section{MATERIAL E MÉTODOS}

Durante o período de abril de 2009 a abril de 2012, foram acompanhados os abates e a inspeções post mortem de bovinos em 10 matadouros-frigoríficos com serviço de inspeção oficial no estado da Bahia. A colheita das lesões sugestivas de tuberculose ou por linfadenites diversas durante a rotina de inspeção das carcaças bovinas foi realizada pelo inspetor médico veterinário, e as amostras foram acondicionadas em frascos contendo solução saturada de borato de sódio $\left(\mathrm{Na}_{2} \mathrm{~B}_{2} \mathrm{O}_{7} \cdot 10 \mathrm{H}_{2} \mathrm{O}\right.$, $140 \mathrm{~g} / \mathrm{L}$ ) como meio conservante, o qual preserva as micobactérias por até 60 dias em temperatura ambiente (Richards e Wright, 1983). As amostras foram enviadas ao setor de tuberculose do Laboratório de Micobacteriologia da Escola de Medicina Veterinária e Zootecnia da Universidade Federal da Bahia para o isolamento e a identificação de micobactérias. As amostras foram descontaminadas pelo cloreto de 1hexadecilpiridinio (HPC) a $1,5 \%$ por $30 \mathrm{~min}$, inoculadas nos meios de cultura StonebrinkLeslie e Lowenstein-Jensen e incubadas a $37^{\circ} \mathrm{C}$ por até 90 dias (Rodriguez, 2005; Brasil, 2008). Colônias observadas no meio de cultura foram coradas pelo método de Ziehl-Neelsen. Dos isolados caracterizados como bacilos álcoolácido resistentes (BAAR), foi realizada uma suspensão bacteriana em $200 \mu \mathrm{L}$ de tampão TE (10mM Tris-HCl; 1mM EDTA; pH 8.0) para inativação da bactéria e extração do DNA por lise térmica por meio de uma incubação a $100^{\circ} \mathrm{C}$ por $30 \mathrm{~min}$.

As condições do ensaio molecular foram realizadas segundo protocolo descrito por Warren et al. (2006), incluindo os desenhos dos primers que são baseados nas regiões genômicas de diferença do complexo Mycobacterium tuberculosis: RD1, RD4, RD9 e RD12. Resumidamente, $2 \mu \mathrm{L}$ de cada amostra, contendo 100ng de DNA, foram aplicados em reações de PCR. As reações continham $0,625 \mathrm{U}$ de Taq
DNA polymerase (HotStarTaq plus DNA polymerase, QIAGEN), tampão de PCR 1X, tampão Q 1X, $2 \mathrm{mM} \mathrm{MgCl}_{2}, 0,4 \mathrm{mM}$ de cada dNTP e $1 \mu \mathrm{M}$ de cada primer. Os controles positivos e negativos foram utilizados em cada reação com o objetivo de se avaliarem os experimentos. As condições da reação no termociclador iCycler iQ5 (Bio-Rad, Hercules, $\mathrm{CA}$ - USA) foram: $95^{\circ} \mathrm{C}$ por cinco minutos; 45 ciclos de $94^{\circ} \mathrm{C}$ por um minuto, $62^{\circ} \mathrm{C}$ por um minuto e $72^{\circ} \mathrm{C}$ por um minuto, seguidos por uma extensão final a $72^{\circ} \mathrm{C}$ por 10 minutos Os produtos de amplificação foram separados por eletroforese $(6 \mathrm{~V} / \mathrm{cm})$ em gel de agarose $3 \%$ em tampão TBE $1 \mathrm{X}$ e visualizados por coloração com SYBR Safe 10.000 vezes diluído.

As etapas de pré-PCR, PCR e pós-PCR foram realizadas em áreas fisicamente separadas para minimizar o risco de contaminação cruzada, e um controle negativo contendo água foi incluído em todas as reações para avaliar o surgimento de contaminação nos reagentes.

\section{RESULTADOS E DISCUSSÃO}

As amostras foram provenientes de 10 matadouros-frigoríficos monitorados no estado da Bahia com serviço de inspeção oficial. Do total de bovinos abatidos, sadios ao exame ante mortem pelo serviço de inspeção oficial, 180 carcaças apresentaram lesões sugestivas de TB ou linfadenites por outras causas durante o exame post mortem, sendo $71 \%$ dessas lesões provenientes de bovinos machos com até 32 meses de idade. A diferença na detecção de lesões sugestivas ou não de tuberculose em carcaças bovinas depende do tempo disponível para examinar cuidadosamente a carcaça e da experiência do inspetor. Desta forma, a precisão ao abate provavelmente varia entre diferentes regiões e matadouros-frigoríficos (Perrez et al., 2002).

As lesões estavam localizadas nos linfonodos da cabeça e do pescoço, assim como nos pulmões e nos linfonodos torácicos, do fígado e do peritônio. Dados similares aos analisados por Gathogo et al. (2012), que inspecionaram 929 carcaças em dois abatedouros no Quênia, observaram que as lesões distribuídas nas carcaças estavam localizadas nos gânglios linfáticos brônquicos e mediastinais, no parênquima pulmonar, no parênquima hepático e 
nos linfonodos localizados em outros tecidos. Enríquez-Cruz et al. (2010) observaram maior quantidade de lesões nos nódulos linfáticos, nos pulmões e no fígado. Durante a inspeção oficial de 3.322 bovinos abatidos em cinco frigoríficos localizados na Etiópia, Biffa et al. (2012) avaliaram 337 carcaças com lesões sugestivas de tuberculose, e as mais frequentes estavam nos pulmões e nos linfonodos respiratórios $(50,9 \%)$, nos linfonodos mesentéricos e intestinais $(16,5 \%)$. Esses resultados descrevem a importância da via respiratória em propagar o bacilo para outros animais suscetíveis, conforme relatado por Lavagnoli et al. (2010).

$\mathrm{Na}$ bacteriologia, $14 \%$ das amostras (25/180) apresentaram crescimento de colônias de coloração creme-amareladas, pequenas, arredondadas, com bordas irregulares, superfície granular em meio de cultura Stonebrink-Leslie, e o tempo médio observado para o aparecimento das colônias foi de 34 dias, sendo o mínimo de 22 e o máximo de 63 dias. Esses resultados são compatíveis com a literatura, que relata o crescimento das primeiras colônias de M. bovis em meio Stonebrink-Leslie em 28 dias (Mota et al., 2001) e 36 dias (Corner, 1994). Os 25 isolados foram submetidos à coloração de ZiehlNeelsen, e todos os esfregaços evidenciaram a presença de bacilos álcool-ácido resistentes. Pela mPCR, Mycobacterium bovis foi identificado em 14/25 (56\%) isolados de acordo com o perfil de amplificação dos produtos esperados para esta espécie, os quais apresentaram amplificações dos fragmentos relativos às regiões RD1 (146pb), RD4 (268pb), RD9 (108pb) e RD12 (306pb) (Fig. 1). As demais amostras, 11/25 (44\%), não apresentaram perfil de amplificação que caracterizassem as cinco espécies do complexo M. tuberculosis avaliadas. Duarte (2010) avaliou esses isolados pelas características fenotípicas e bioquímicas e observou uma frequência de $64 \%$ (7/11) de complexo $M$. terrae, $27 \%$ (3/11) de $M$. fortuitum e $9 \%(1 / 11)$ de $M$. kansasii nas amostras. Segundo Corner (1994), o diagnóstico bacteriológico é considerado "padrão ouro", apesar de requerer métodos de descontaminação agressivos, que podem afetar o crescimento das micobactérias, além de um longo período para o crescimento das primeiras colônias e identificação da espécie. Deste modo, a mPCR permitiu a identificação do M. bovis de forma rápida e simples, e, levando-se em consideração a sua alta especificidade, a técnica poderia auxiliar os programas de controle e erradicação da tuberculose. Furlanetto et al. (2012) também associaram o uso da mPCR no diagnóstico da tuberculose bovina em linfadenites observadas durante o abate de bovinos em matadourosfrigoríficos no estado do Mato Grosso e detectaram a presença de DNA de $M$. bovis em $7 \%$ (14/198) das amostras, o que demonstra ser esta uma técnica versátil, rápida e capaz de contribuir para a detecção de focos remanescentes de tuberculose, acelerando o processo de controle e erradicação da doença no rebanho.

Em Minas Gerais, a prevalência da tuberculose foi de $0,07 \%$ em 954.640 bovinos abatidos entre 1993 e 1997, em 10 matadouros sujeitos à inspeção federal, e a região sudoeste foi a que apresentou maior prevalência de tuberculose $(0,17 \%)$, associada ao fato de esta ser uma região predominantemente de gado leiteiro (Baptista $e t$ al., 2004). Desta forma, o reduzido número de isolados de $M$. bovis (14) em bovinos abatidos em matadouros-frigoríficos do estado da Bahia pode estar relacionado ao caráter crônico da enfermidade, o que dificulta a observação de lesões post mortem em animais mais jovens (O’Reilly e Daborn, 1995; OIE, 2012), além da predominância do sistema de criação extensiva, voltada para a pecuária de corte. Em São Paulo, Rodriguez (2005) relatou que a cada 100 animais condenados por tuberculose em frigoríficos com serviço de inspeção federal (SIF), 36 estavam realmente infectados, enquanto na rede de inspeção estadual, esse valor foi de 65 animais. Essa menor prevalência de tuberculose na rede SIF foi devido ao fato de o abate ser quase exclusivamente de bovino de corte, de criação extensiva, em que a $\mathrm{Tb}$ tem ocorrência esporádica. Associada a esses fatores, a prevalência de animais reatores à tuberculina pelo teste cervical comparativo no estado da Bahia foi de 0,21\% (0,07-0,6\%) (Costa, 2012). 


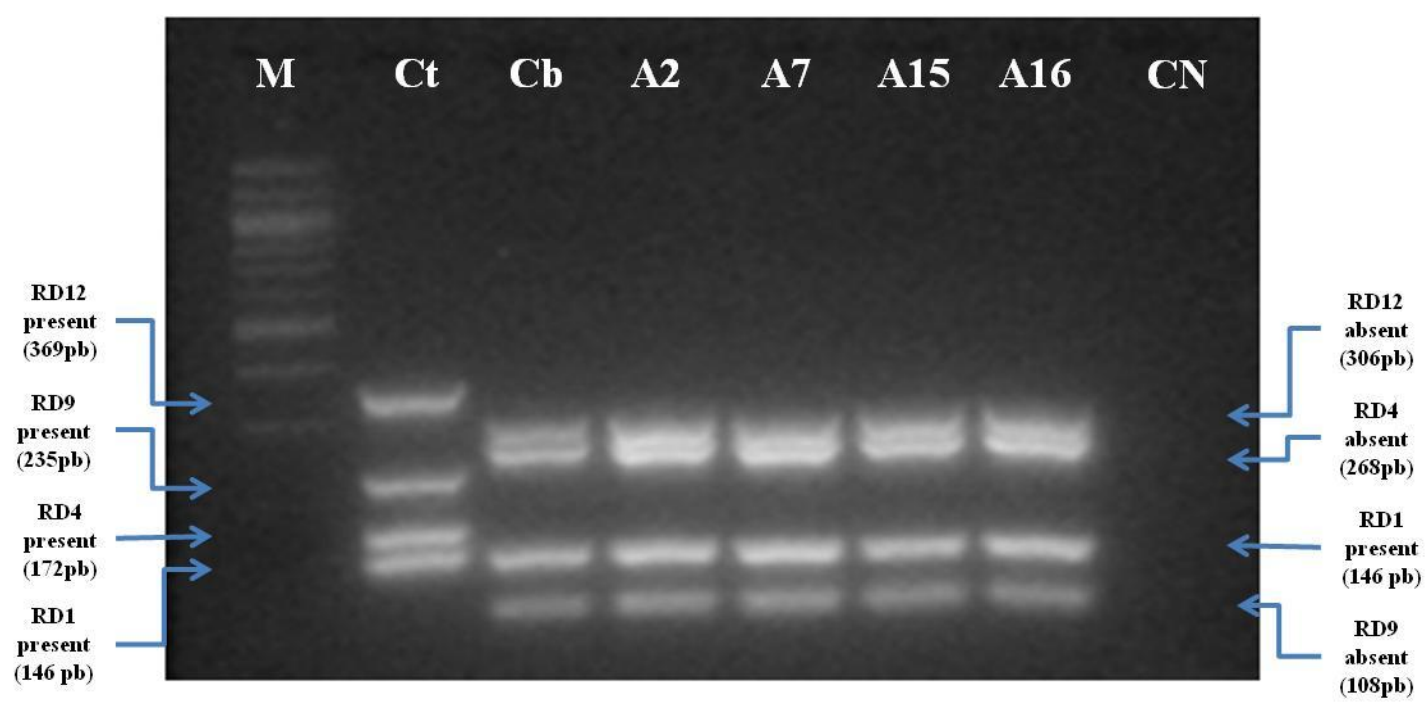

Figura 1. Perfil de amplificação de Mycobacterium bovis por m-PCR de isolados de cultivo bacteriano. M, marcador de peso molecular 100bp; Ct, controle positivo Mycobacterium tuberculosis H37Rv; Cb, controle positivo Mycobacterium bovis AN5; A2, A7, A15 e A16, amostras positivas para M. bovis; CN, controle negativo (água).

\section{CONCLUSÕES}

Neste estudo, a associação entre a inspeção post mortem de rotina em matadouros- frigoríficos e o diagnóstico molecular (mPCR) foi eficiente na identificação do $M$. bovis de cepas isoladas de cultivo bacteriano provenientes de fragmentos de tecidos lesionados, o que possibilitou a adoção de medidas sanitárias em curto período de tempo. A atual infraestrutura dos matadourosfrigoríficos no estado da Bahia, associada ao status sanitário de baixa prevalência da tuberculose bovina, permite a implantação de um sistema de vigilância epidemiológica para detecção dessa enfermidade em propriedades foco. Essa metodologia parece ser uma estratégia adequada para adiantar o processo de erradicação no estado, mas exige maior integração entre os serviços de inspeção e os laboratórios de diagnóstico.

\section{AGRADECIMENTOS}

Ao CNPq e à CAPES, pelo suporte financeiro; à Agência de Defesa Agropecuária do Estado da Bahia (ADAB), pela colaboração na obtenção de informações e de amostras nos matadourosfrigoríficos do estado da Bahia; e aos programas de pós-graduação em Ciência Animal nos Trópicos (EMVZ-UFBA), em biotecnologia
(Renorbio-UFBA) e em Imunologia (PPGIm UFBA), pelo suporte educacional.

\section{REFERÊNCIAS}

ADAMS, A.P.; BOLIN, S.R.; FINE A.E. et al. Comparison of PCR versus culture for detection of Mycobacterium bovis after experimental inoculation of various matrices held under environmental conditions for extended periods. Appl. Environ. Microbiol., v.79, p.6501-6506, 2013.

ARAÚJO, C.P. Isolamento de Mycobacterium bovis em cultura e sua identificação pela reação de polimerase em cadeia. 2004, 52f. Dissertação (Mestrado em Ciência Animal). Universidade Federal de Mato Grosso do Sul, Campo Grande.

BAPTISTA, F.; MOREIRA， E.C.; SANTOS, W.L.M.; NAVEDA, L.A.B. Prevalência da tuberculose em bovinos abatidos em Minas Gerais. Arq. Bras. Med. Vet. Zootec., v.56, p.577-580, 2004

BIFFA, D.; BOGALE, A. GODFROID, J.; SKJERVE, E. Factors associated with severity of bovine tuberculosis in Ethiopian cattle. Trop Anim Health Prod., v.44, p.991-998, 2012. 
BIFFA， D.; BOGALE， A.; SKJERVE， E. Diagnostic efficiency of abattoir meat inspection service in Ethiopia to detect carcasses infected with Mycobacterium bovis: Implications for public health. BMC Public Health, v.10, p.462474, 2010.

BRASIL. Ministério da Agricultura, Pecuária e Abastecimento. Programa Nacional de Controle e Erradicação da Brucelose e Tuberculose Animal - PNCEBT. Brasília, 2006. 188p.

BRASIL. Ministério da Saúde. Manual Nacional de Vigilância Laboratórial da Tuberculose e outras Micobacterias. Ministério da Saúde, Brasília. 2008, 436p.

CARDOSO, M.A.; CARDOSO, R.F.; HIRATA, R.D.C. et al. Direct Detection of Mycobacterium bovis in Bovine Lymph Nodes by PCR. Zoonoses Publ. Health, v.56, p.465-470, 2009.

CORNER, L.A. Post mortem diagnosis of Mycobacterium bovis infection in cattle. Vet. Microbiol., v.40, p.53-63, 1994.

COSTA, L.B. Caracterização da tuberculose bovina em regiões de relevância econômica no Estado da Bahia. 2012, 121f. Dissertação (Mestrado em Ciência Animal nos Trópicos). Escola de Medicina Veterinária, Universidade Federal da Bahia, Salvador.

DUARTE, L.F.C. Investigação de Mycobacterium bovis em bovinos abatidos no município de Feira de Santana, Bahia. 2010, 61f. Dissertação (Mestrado em Ciência Animal nos Trópicos). Escola de Medicina Veterinária, Universidade Federal da Bahia, Salvador.

ENRÍQUEZ-CRUZ, C.; CRUZ-HERNÁNDEZ, N.I.; ZERTUCHE-RODRÍGUEZ, J.L. et al. Epidemiology of bovine tuberculosis in Mexico, bordering the United States, at establishment of controlling strategies. Arq. Bras. Med. Vet. Zootec., v.62, p.1029-1035, 2010.

FURLANETTO, L.V.; FIGUEIREDO, E.E.S.; CONTE JÚNIOR, C.A. et al. Uso de métodos complementares na inspeção post mortem de carcaças com suspeita de tuberculose bovina. Pesq. Vet. Bras., v.32, p.1138-1144, 2012.

GATHOGO, S.M.; KURIA, J.K.N.; OMBUI, J.N. Prevalence of bovine tuberculosis in slaughter cattle in Kenya: a postmortem, microbiological and DNA molecular study. Trop. Anim. Health Prod., v.44, p.1739-1744, 2012.
HEINEMANN, M.B.; MOTA, P.M.P.C.; LOBATO, F.C.F. et al. Tuberculose bovina: uma introdução à etiologia, cadeia epidemiológica, patogenia e sinais clínicos. Cad. Tec. Vet. Zootec., v.59, p.1-12, 2008.

INSTITUTO Brasileiro de Geografia e Estatística. Efetivos dos rebanhos de grande porte em 31.12, segundo as Grandes Regiões e Unidades da Federação - 2010. Disponível em: <http://www.ibge.gov.br/home/estatistica/economia/p pm/2010/tabelas_ pdf/tab03.pdf $>$. Acessado em: 29 set. 2012.

KANTOR, I.N.; RITACCO, V. An update on bovine tuberculosis programmes in Latin American and Caribbean countries, Vet. Microbiol., v.112, p.111-118, 2006.

LAVAGNOLI, M.R.; AMORIM, B.M.; MACHADO, G.P. et al. Tuberculose em bovinos no Estado do Espírito Santo. Vet. e Zootec., v.17, p.71-78, 2010.

MOTA, P.M.P.C.; LOBATO, F.C.F.; ASSIS, R.A. et al. Isolamento de Mycobacterium bovis em cão. Arq. Bras. Med. Vet. Zootec., v.53, p.13, 2001 .

OIE. Bovine tuberculosis. In: Manual of Diagnostic Tests and Vaccines for Terrestrial Animals, 2012. Disponível em: <http://www.oie.int/fileadmin/Home/eng/Health _standards/tahm/2.04.07_BOVINE_TB.pdf>. Acessado em: 26 set. 2012.

OLIVEIRA, V.M.; FONSECA, A.H.; PEREIRA, M.J.S. et al. Análise retrospectiva dos fatores associados à distribuição da tuberculose bovina no estado do Rio de Janeiro. Arq. Bras. Med. Vet. Zootec., v.60, p.574-579, 2008.

O'REILLY, L.M.; DABORN, C.J. The epidemiology of Mycobacterium bovis in animals and man: a review. Tubercle and Lung Dise., v.76, p.1-46, 1995.

PACHECO, A.M.; HAMZÈ, A.L.; AVANZA, M.F.B. et al. Tuberculose bovina - relato de caso. Rev. Cient. Elet. de Med. Vet., n. 13, 2009. Disponível em: <http://faef.revista.inf.br/site/ a/927-tuberculose-bovina-relato-de-caso.html >. Acessado em: 28 ago. 2013. 
PERREZ, A.M.; WARD, M.P.; TORRES, P.; RITACCO, V. Use of spatial statistics and monitoring data to identify clustering of bovine tuberculosis in Argentina. Prev. Vet. Med., v.56, p.63-74, 2002.

RICHARDS, W.D.; WRIGHT, H.S. Preservation of tissue specimens during transport to mycobacteriology laboratories. J. Clin. Microbiol., v.17, p.393-395, 1983.
RODRIGUEZ, C.A.R. Sistema de detecção de focos de tuberculose bovina no Estado de São Paulo utilizando métodos moleculares $e$ epidemiológicos. 2005, 86f. Tese (Doutorado em Epidemiologia Experimental e Aplicada às Zoonoses) - Faculdade de Medicina Veterinária e Zootecnia, Universidade de São Paulo, São Paulo.

WARREN, R.M.; GEY VAN PITTIUS, N.C.; BARNARD, M. et al. Differentiation of Mycobacterium tuberculosis complex by PCR amplification of genomic regions of difference. Int. J. Tuberc. Lung Dis., v.10, p.818-822, 2006. 